\title{
Outcomes of acute upper gastrointestinal bleeding in relation to timing of endoscopy and the experience of endoscopist: a tertiary center experience
}

Authors

Institutions
Noor Mohammed ${ }^{1,2}$, Amer Rehman ${ }^{1}$, Mark Thomas Swinscoe ${ }^{3}$, Pradeep Mundre ${ }^{1}$, Bjorn Rembacken ${ }^{1}$

1 Department of Gastroenterology, St James's University Hospital, Leeds Teaching Hospitals NHS Trust, Leeds, UK

${ }^{2}$ Leeds Institute of Biomedical and Clinical Sciences, University of Leeds, Leeds, UK

${ }^{3}$ Department of Colorectal Surgery, St James's University Hospital, Leeds Teaching Hospitals NHS Trust, Leeds, UK submitted 16. June 2015 accepted after revision 15. December 2015

\section{Bibliography}

DOI http://dx.doi.org/

10.1055/s-0042-100193

Published online: 3.3.2016

Endoscopy International Open 2016; 04: E282-E286

(c) Georg Thieme Verlag KG Stuttgart · New York

E-ISSN 2196-9736

\section{Corresponding author}

\section{Noor Mohammed, MBBS MRCP}

Department of

Gastroenterology

St James's University Hospital

Leeds Teaching Hospitals NHS

Trust

Leeds LS12 4DJ

UK

Fax: +44-113-2068851

Noor.Mohammed@doctors.org. uk

\section{License terms}

Introduction: Patients with gastrointestinal bleeding admitted out of hours or at the weekends may have an excess mortality rate. The literature reports around this are conflicting.

Aims and methods: We aimed to analyze the outcomes of emergency endoscopies performed out of hours and over the weekends in our center. We retrospectively analyzed data from April 2008 to June 2012.

Results: A total of 507 'high risk' emergency gastroscopies were carried out over the study period for various indications. Patients who died within 30 days of the index procedure [22\% (114/510)] had a significantly higher Rockall score (7.6 vs. 6.0, $P<0.0001)$, a higher American Society of Anesthesiologists (ASA) status (3.5 vs. 2.7, $P<0.001$ ), and a lower systolic blood pressure (BP) at the time of the examination ( 94.8 vs $103, P=0.025$ ).

\section{Background}

$\nabla$

There is some evidence that patients admitted to hospitals during weekends are more likely to die [1-8]. In the UK, this has led to calls from the Royal Colleges and Medical Education England for greater consultant presence at the weekend [9-13]. Indeed, the new NHS Commissioning Board is currently considering steps to improve emergency and urgent care at weekends [14]. The work has broad support by the Academy of Medical Royal Colleges [12] and the individual Royal Colleges $[15,16]$. However, the evidence for an increased mortality rate at night and weekends is equivocal. Goldacre and Maisonneuve found that there was no evidence of excess deaths from meningococcal disease at weekends [17]. Furthermore, there is evidence that routine, elective care can be less safe when provided at weekends [18].

Upper gastrointestinal bleeding is a medical emergency associated with a mortality of up to $10 \%$ [19-23]. A UK-wide audit in 2007 highligh-
These patients were significantly older (77.7 vs. 67.5 years, $P=0.006)$, and required more blood transfusion (5.9 versus 3.8 units). Emergency out-of-hours endoscopy was not associated with an increased risk of death [relative risk (RR) 1.09, $95 \%$ confidence interval (CI) $1.12-1.95$ ]. Whether the examination was carried out by a senior specialist registrar (senior trainee) or a consultant made no difference to the survival of the patient (RR 0.98, CI 0.77-1.32).

Conclusion: Higher pre-endoscopy Rockall score and ASA status contributed significantly to the 30-day mortality following upper gastrointestinal bleeding, whereas lower BP tended towards significance. Outcomes did not vary with the time of the endoscopy nor was there any difference between a consultant and a senior specialist registrar led service.

ted significant deficiencies in the care provided for patients who presented with upper gastrointestinal bleeding [24]. Outcomes were less good for patients attending hospitals where there was a lack of on-call consultant led endoscopy in the out-of-hours setting.

Previous studies of out-of-hours endoscopy for acute gastrointestinal bleeding have reached conflicting conclusions. Some found an increased mortality rate at weekends [25-27] whereas other studies have detected no such difference [28-31]. There are several possible explanations for these inconsistencies in findings; some studies have derived data from large databases with limited clinical details, others have not made any distinction between elective and emergency weekend admissions, only a few have included weekday nights as being "out-of-hours" admissions, and some studies have not included deaths after discharge from hospital. Finally, almost all studies have not included inpatients although these have by far the greatest mortality. 
The upper gastrointestinal bleeding service at Leeds provides a full range of endoscopic, radiological, and surgical treatment options and fulfils the nine service standards in the document "Scope for Improvement" published by the academy of Medical Royal Colleges. The majority of emergency endoscopies in Leeds are carried out by senior specialist registrars who are fully trained, assessed, and signed off in the endoscopic management of gastrointestinal bleeding.

\section{Methods}

We retrospectively reviewed electronic databases to determine whether patients presenting with acute upper gastrointestinal hemorrhage in the evenings, weekends, and bank holidays suffered an excess mortality compared to patients undergoing emergency endoscopy during normal working hours. We looked at the differences in mortality when the procedure was conducted by a gastroenterologist or a senior specialist registrar.

The primary outcome was 30-day mortality and secondary outcomes included rebleeding rates, volume of blood transfusion, and secondary interventions such as use of balloon tamponade, emergency surgery, and radiological interventions including transjugular intrahepatic portosystemic shunts (TIPSS). We also recorded if there was any deviance from the current guidelines while managing upper gastrointestinal bleeding.

Patients with only "high risk findings" were included in the final analysis. This included any bleeding site in the upper gastrointestinal tract with stigmata of recent hemorrhage such as fresh blood, clots or hematin. "Out-of-hours" included the night-time (20:00 to 08:00) and weekends (Friday 20:00 to Monday 08:00) and public holidays.

Senior specialist registrars were "signed off" to be independent endoscopists in managing acute upper gastrointestinal bleeding by two experienced endoscopists on separate occasions locally. Consultants (those who had received a 'certificate of completion of training' from the Royal College of Physicians) were independent endoscopists. Procedures done by those endoscopists accredited with Joint Advisory Group (JAG), a regulatory body in the UK for maintaining high standards in endoscopy, were included. Patient demographic details, admission details, comorbidities, and records of all endoscopic/radiological/surgical interventions were extracted from the electronic hospital records. The hospital transfusion database was interrogated to determine the number of units of blood issued to each patient. The surgical and radiological databases were searched to determine the outcomes after angiographic embolization or emergency surgery.

\section{Results}

$\nabla$

A total of 35821 gastroscopies were carried out between April 2008 and June 2012 of which 5\% (1853/35821) were emergency gastroscopies carried out for suspected upper gastrointestinal bleeding. In a quarter of the emergency procedures (507/1853), there was a "high risk" finding. This proportion of high risk findings, found amongst all emergency endoscopies, was the same as in the National Audit of 2007. The 507 high risk findings comprised 193 duodenal ulcers (10\% with a spurting vessel, 30\% with an oozing vessel, $33 \%$ with a visible vessel, and $27 \%$ with a fresh clot), 106 bleeding gastric ulcers (7\% with a spurting vessel, $19 \%$ with an oozing vessel, $36 \%$ with a visible non-bleeding ves- sel, and 38\% with a fresh clot), 162 esophageal varices, 20 gastric varices, and 26 "other lesions" (12 Dieulafoy lesions, three esophageal ulcers with a fresh clot, one oozing biopsy site, one bleeding polypectomy site, one case of bleeding from a gastric lymphoma, three cases of oozing from hemorrhagic portal hypertensive gastropathy, three cases of actively bleeding angioectasia, one oozing gastric cancer, and one actively bleeding duodenal endoscopic mucosal resection (EMR) site).

A total of 124 (24\%) emergency endoscopies were carried out during a weekend or public holiday and 151 (30\%) were carried out at night. A total of 112 patients (22\%) died within 30 days of the emergency endoscopy.

\section{Mortality}

Using data from the National Mortality database, we found that following $22 \%$ of these highly selected procedures, the patient had died within 30 days (112/507) of the initial endoscopy. Patients who died were significantly older than those who survived (average age 77.7 vs. 67.5 years, $P=0.006$ ). Patients who died also had significantly more comorbidities as measured by their ASA score than those who survived (average ASA 3.5 vs. $2.7, P<0.001)$. At the time of the emergency endoscopy, patients who ultimately died had a lower systolic blood pressure than those who survived (average systolic BP of $94.8 \mathrm{vs} 103 \mathrm{~mm} / \mathrm{Hg}$, $P=0.025$ ) and a higher Rockall score (average 7.6 vs. 6.0, $P<0.0001$ ). However, patients who died had received significantly more blood than those who survived (average of 5.9 units vs. 3.8 units of blood transfused).

There was no significant difference in mortality between the different types of bleeding lesion, level of hemoglobin at the time of gastroscopy ( 8.0 vs. $7.8 \mathrm{~g} / \mathrm{dL}$ ), or heart rate (100 vs. $102 \mathrm{bpm}$ ) between patients who survived and those who died.

Overall, one-fifth of patients (113/507 patients), suffered a rebleed following initial endoscopic intervention ( $\bullet$ Table 1$)$. Of the 113 patients who suffered a rebleed, 51 patients died and only 62 survived. In a total of 28 cases, hemostasis failed and the patient was referred for emergency radiological embolization of the bleeding site. This group of patients had suffered a significantly greater blood loss and their hemoglobin level had dropped to an average $\mathrm{Hb}$ of $6.9 \mathrm{~g} / \mathrm{dL}$ in spite of having received an average of 12.9 units of blood. In spite of this, the group referred for angiography did unexpectedly well and 22 patients were alive at 30 days.

A total of 151 patients underwent an emergency gastroscopy at night and a further 124 patients underwent the emergency endoscopy during a weekend or a public holiday. These patients were not found to have an increased risk of dying $(P=0.50$, $P=0.32$, respectively) compared to patients undergoing endoscopy during the day or during weekdays ( $\bullet$ Table 2 ). Whether the initial emergency endoscopy procedure was carried out by a senior trainee (403 cases) or a consultant (104 cases) made no difference to the survival of the patient $(P=0.40)(\checkmark$ Table 3$)$.

\section{Peptic ulcer bleeding}

In accordance with recommendations by the British Society of Gastroenterology, the standard endoscopic therapy in Leeds is to treat bleeding ulcers with injection of dilute adrenaline (1:10 000) followed by thermal therapy - Argon Plasma Coagulation or bipolar diathermy, and/or ligation clips.

In 34 cases, our guidelines had not been followed. There was usually a valid reason for this; no discrete bleeding site to target in a large peptic ulcer ( 14 cases), the patient became too restless 
Table 1 Overview of lesions and their mortality rate.

\begin{tabular}{|lcl|}
\hline & Rebleeding (\%) & Mortality within 30 days (\%) \\
\hline Duodenal ulcer & $38 / 193(20 \%)$ & $35 / 193(18 \%)$ \\
\hline Gastric ulcer & $20 / 106(19 \%)$ & $24 / 106(23 \%)$ \\
\hline Esophageal varices & $47 / 162(29 \%)$ & $44 / 162(27 \%)$ \\
\hline Gastric varices & $3 / 20(15 \%)$ & $3 / 20(15 \%)$ \\
\hline Other lesions & $5 / 26(19 \%)$ & $6 / 26(23 \%)$ \\
\hline
\end{tabular}

Table 2 30-day mortality versus time of endoscopy.

\begin{tabular}{|l|clll|}
\hline & $\begin{array}{l}\text { Weekday } \\
\text { procedure }\end{array}$ & $\begin{array}{l}\text { Weekend } \\
\text { procedure }\end{array}$ & $\begin{array}{l}\text { Daytime } \\
\text { procedure }\end{array}$ & $\begin{array}{l}\text { Night-time } \\
\text { procedure }\end{array}$ \\
\hline Patients survived & 294 & 101 & 273 & 122 \\
\hline Patients deceased & 89 & 23 & 83 & 29 \\
\hline
\end{tabular}

Table 3 Case mix and outcomes following procedures by registrars and consultants.

\begin{tabular}{|lll|}
\hline & Registrar & Consultant \\
\hline $\begin{array}{l}\text { Total number of procedures } \\
\text { Number of procedures outwith normal }\end{array}$ & 403 & 104 \\
working hours & $257(64 \%)$ & $14(17 \%)$ \\
\hline Number of peptic ulcer bleeds & $255(63 \%)$ & $44(42 \%)$ \\
\hline Number of variceal bleeds & $129(32 \%)$ & $54(52 \%)$ \\
\hline Number of pts alive after 30 days & $317(79 \%)$ & $78(75 \%)$ \\
\hline Management not according to guidelines & $10(2.5 \%)$ & $3(2.9 \%)$ \\
\hline Number of rebleeds & $87(22 \%)$ & $26(25 \%)$ \\
\hline
\end{tabular}

to continue under sedation alone (five cases) and the procedure had to be rescheduled immediately under general anesthesia, or the bleeding was deemed too brisk for endoscopic intervention (three cases) and the patient was referred for emergency angiographic embolization. In three cases, an actively spurting artery was injected with human thrombin rather than adrenaline. Diathermy was withheld in two patients with pacemakers of an uncertain type when only unipolar diathermy was available. In a further four cases, clips alone were used to close small gastric ulcers.
However, in $3 \%$ of cases (seven cases of 299 peptic ulcer bleeds), there did not appear to be any reason why the endoscopists had departed from the management guidelines. In two of these cases, a consultant made the decision and in five cases, the decision was made by a senior specialist registrar ( Table 4 ). This difference was not statistically significant.

The 7-day rebleeding rate for duodenal ulcers was 20\% (38/193) and $19 \%$ for gastric ulcers (20/106). Five patients with rebleeding from a peptic ulcer were managed surgically (all were alive 30 days later). A total of 28 patients were referred for angiography and embolization, seven cases because the bleeding could not be stopped endoscopically and in 21 cases, because of rebleeding after the application of full endoscopic therapy. Twenty-two patients were alive 30 days following referral for angiography. Three patients underwent surgery following referral for angiography, two as embolization failed to stop the bleeding and one patient who developed a perforated antrum 3 weeks after embolization of the gastro-duodenal artery and the inferior pancreatico-duodenal artery, a recognized complication [32].

\section{Variceal hemorrhage}

In a total of 162 emergency procedures, the bleeding originated from esophageal varices and in a further 20 cases, from gastric varices.

The endoscopic management was in agreement with our management guidelines in $97 \%$ of cases (176/181). In five cases, our guideline to treat varices with either injection of ethanolamine or variceal band ligation had not been adhered to. The 7-day rebleeding rate for esophageal varices was $29 \%$ (47/162), and $15 \%$ for gastric varices $(3 / 20)$

\section{Discussion \\ $\nabla$}

Several previous studies of out-of-hours endoscopy for acute gastrointestinal bleeding have reported a $10-20 \%$ increased mortality rate at the weekends [25-27]. Shaheen et al. [25] reported a mortality rate of $3.4 \%$ for weekend versus $3.02 \%$ for weekday admission. However, only peptic ulcer related bleeds were included in the study and the authors only reported 7-day mortality rates. They reported that patients admitted over the weekend had a delay in undergoing an endoscopic procedure. In a more recent

Table 4 Details of cases where management deviated from guidelines.

\begin{tabular}{|c|c|c|}
\hline & Level of endoscopist & Rebleeding \\
\hline Duodenal ulcer with a protruding clot treated with injection only & Registrar & No \\
\hline Duodenal ulcer with protruding clot. No therapy applied & Registrar & No \\
\hline Duodenal ulcer with a flat spot; not treated as no visible blood or hematin staining in the stomach & Registrar & Yes \\
\hline Duodenal ulcer with a flat spot treated with injection only & Consultant & No \\
\hline $\begin{array}{l}\text { Gastric ulcer with a fresh clot; only treated with thermal therapy. Adrenaline was avoided as patient was already } \\
\text { tachycardic and had severe ischemic heart disease }\end{array}$ & Registrar & No \\
\hline Gastric ulcer with a flat spot and hematin staining in stomach; not treated & Consultant & Yes \\
\hline Gastric ulcer with fresh clot; no therapy applied & Registrar & Yes \\
\hline $\begin{array}{l}\text { Bleeding esophageal varices treated with the insertion of a Sengstaken tube rather than an attempt at banding or } \\
\text { sclerotherapy }\end{array}$ & Registrar & No \\
\hline $\begin{array}{l}\text { Bleeding varix on greater gastric curve mistaken for a bleeding Dieulafoy lesion and incorrectly treated with bipolar } \\
\text { diathermy rather than with histoacryl injection }\end{array}$ & Registrar & No \\
\hline Esophageal and gastric varices but not treated as no stigmata of recent bleeding and no blood in the stomach & Registrar & No \\
\hline Esophageal varices and black fluid in stomach but not treated & Registrar & No \\
\hline Esophageal varix with no stigmata and no blood in the stomach & Registrar & Yes \\
\hline Dieulafoy lesion in the stomach; not treated & Registrar & No \\
\hline
\end{tabular}


large scale retrospective study from the United States [28], there was no difference in mortality among patients with upper gastrointestinal bleeding (variceal and non-variceal) during the weekends compared to weekdays. A similar observation was made by Kalaitzakis et al. from Sweden [33]. In both of these studies, a lower rate of endoscopies was noted over the weekend. Other studies from Europe [29,30] and Hong Kong [31] also failed to detect an effect on mortality in patients admitted during weekends. However, most of these studies focused on the in-hospital mortality rather than the overall 30-day mortality. These shortcomings in the published studies may explain the variability in the outcomes reported.

A prospective study from Europe found that patients admitted with gastrointestinal bleeding during weekends were three times more likely to die within 30 days of admission [34]. In contrast, an earlier prospective study from the UK had found that patients admitted during weekends were more poorly and suffered a delay in time to endoscopy but in spite of this, both the in-hospital mortality rate and rebleeding rate remained stable at 10\% [35]. Similar observations to ours were reported by Nahon et al. [30] in their prospective observational study where, at the weekend, oncalls were supported by the senior gastroenterological team member and the outcomes were better than for the weekdays.

In contrast, our study looked at upper gastrointestinal bleeding from all causes and we reported 30-day mortality rates. We have a robust emergency endoscopy service with 24/7 cover by a three-tier system for doctors and nurses alike. In our center, all patients with acute upper gastrointestinal bleeding will undergo an emergency endoscopy within 6 hours. We looked at each of our significant cases of emergency gastrointestinal bleeding to determine the parameters which were associated with worse outcomes. Conceivably, the risk factors for increased mortality were increasing age, multiple comorbidities, high ASA status, and hemodynamic parameters.

The weaknesses of this study include its retrospective design and not having a control group. However, since the majority of the emergency endoscopies (74\%) were performed during the out of hours period, we do not think that the results with a control group would have been any different. This is due to the fact that, even during working hours, we run a similar three-tier working system in the endoscopy department. A further prospective trial is being considered including this factor.

The endoscopic management was according to the local and national guidelines in almost all cases. Where a small number of cases deviated from the guidelines, the management was felt entirely reasonable in those difficult situations.

We had anticipated that patients undergoing emergency endoscopy "out of hours" would have an increased risk of dying, perhaps because they were less stable or more ill than patients undergoing an emergency endoscopy during normal working hours. We found no statistically significant differences in outcomes. Furthermore, whether the procedure was carried out by a consultant or a senior specialist registrar did not affect outcomes.

\section{Competing interests: None}

\section{References}

1 NHS Outcomes Framework 2011 to 2012. www.dh.gov.uk/en/Publicationsandstatistics/Publications/PublicationsPolicyAndGuidance/ DH_122944

2 Bell CM, Redelmeier DA. Mortality among patients admitted to hospital on weekends as compared with weekdays. NEJM 2001; 345: 663-668

3 Aylin P, Yunnis A, Bottle A et al. Weekend mortality for emergency admissions. A large, multi centre study. Qual. Saf Health Care 2010; 19: $213-217$

4 Barba R, Losa JE, Velasco $M$ et al. Mortality among adult patients admitted to the hospital on weekends. Eur J Intern Med 2006; 17: 322 - 324

5 Freemantle N, Richardson M, Wood J et al. Weekend hospitalization and additional risk of death: an analysis of inpatient data. J R Soc Med 2012; 105: 274-284

6 Cram P, Hillis SL, Barnett $M$ et al. Effects of weekend admission and hospital teaching status on in-hospital mortality. Am J Med 2004; 117: $151-177$

7 Cavallazzi R, Marik PE, Hirani A et al. Association between time of admission to the ICU and mortality: a systematic review and metaanalysis. Chest 2010; 138: $68-75$

8 Schmulewitz L, Proudfoot A, Bell D. The impact of weekends on outcome for emergency patients. Clin Med 2005; 5: 621-625

9 Temple J. Time for training. 2010: https://www.gov.uk/government/ uploads/system/uploads/attachment_data/file/213214/FINAL-PDF-revised-for-DH.pdf

10 Collins J. Foundation for excellence: an evaluation of the foundation programme. 2010: http://www.agcas.org.uk/assets/793-Foundationfor-Excellence-An-Evaluation-of-the-Foundation-Programme-downloads

11 Health Education England. Better training, better care. https://hee. nhs.uk/our-work/hospitals-primary-community-care/learning-besafer/better-training-better-care-btbc

12 Academy of Royal Colleges. Seven day consultant present care. http:// www.aomrc.org.uk/cat_view/15-reports-guidance

13 Royal College of Physicians. Position statement: care of medical patients out of hours. 2010: https://www.rcplondon.ac.uk/guidelinespolicy/acute-care-toolkit-1-handover

14 NHS Commissioning Board. Everyone counts: planning for patients 2013/14. 2012: www.commissioningboard.nhs.uk/files/2012/12/everyonecounts-planning.pdf

15 Royal College of Obstetricians and Gynaecologists. High quality women's healthcare. 2011: https://www.rcog.org.uk/en/guidelines-research-services/guidelines/high-quality-womens-health-care/

16 Royal College of Surgeons of England. Reshaping surgical services: principles for change. 2013: https://www.rcseng.ac.uk/publications/ docs/reshaping-surgical-services/

17 Goldacre MJ, Maisonneuve JJ. Mortality from meningococcal disease by day of the week: English national linked database study.J Public Health (Oxf) 2013; 35: 413-421

18 Weekend admission to hospital has a higher risk of death in the elective setting than in the emergency setting: a retrospective database study of national health service hospitals in England. BMC Health Serv Res 2012; 12: 87

19 van Leerdam ME. Epidemiology of acute upper gastrointestinal bleeding. Best Pract Res Clin Gastroenterol 2008; 22: 209-224

20 Hearnshaw $S A$, Logan $R F$, Lowe $D$ et al. Acute upper gastrointestinal bleeding in the UK: patient characteristics, diagnoses and outcomes in the 2007 UK audit. Gut 2011; 60: 1327-1335

21 Sung JJ, Tsoi KK, Ma TK et al. Causes of mortality in patients with peptic ulcer bleeding: a prospective cohort study of 10,428 cases. Am J Gastroenterol 2010; 105: 84-89

22 Blatchford O, Davidson LA, Murray WR et al. Acute upper gastrointestinal haemorrhage in west of Scotland: case ascertainment study. BMJ 1997; 315: $510-514$

23 Rockall TA, Logan RF, Devlin HB et al. Incidence and mortality for acute upper gastrointestinal haemorrhage in the United Kingdom. Steering Committee and members of the National Audit of Acute Upper Gastrointestinal Haemorrhage. BMJ 1995; 311: $222-226$

24 Hearnshaw $S A$, Logan $R F$, Lowe $D$ et al. Use of endoscopy for management of acute upper gastrointestinal bleeding in the UK: results of a nationwide audit. Gut 2010; 59: $1022-1029$

25 Shaheen AA, Kaplan GG, Myers RP. Weekend versus weekday admission and mortality from gastrointestinal hemorrhage caused by peptic ulcer disease. Clin Gastroenterol Hepatol 2009; 7: 303-310 
26 Ananthakrishnan AN, McGinley EL, Saeian K. Outcomes of weekend admissions for upper gastrointestinal hemorrhage: a nationwide analysis. Clin Gastroenterol Hepatol 2009; 7: 296-302e1

27 Dorn SD, Shah ND, Berg BP et al. Effect of weekend hospital admission on gastrointestinal hemorrhage outcomes. Dig Dis Sci 2010; 55: $1658-1666$

28 Abougergi MS, Travis AC, Saltzman JR. Impact of day of admission on mortality and other outcomes in upper GI hemorrhage: a nationwide analysis. Gastrointest Endosc 2014; 80: 228-235

29 Schmulewitz L, Proudfoot A, Bell D. The impact of weekends on outcome for emergency patients. Clin Med 2005; 5: 621-625

30 Nahon S, Pariente A, Latrive JP. Weekend admission does not influence the mortality of upper gastrointestinal bleeding caused by peptic ulcers: results of a French prospective study of the association nationale des gastroentérologues des hôpitaux généraux group. Clin Gastro Hepatol 2009; 7: 911

31 Tsoi KK, Chiu PW, Chan FK et al. The risk of peptic ulcer bleeding mortality in relation to hospital admission on holidays: a cohort study on
8,222 cases of peptic ulcer bleeding. Am J Gastroenterol 2012; 107 : 405- 410

32 Bell SD, Lau KY, Sniderman KW. Synchronous embolization of the gastroduodenal artery and the inferior pancreaticoduodenal artery in patients with massive duodenal hemorrhage. J Vasc Interv Radiol 1995; 6: $531-536$

33 Kalaitzakis E, Helgeson J, Strömdahl M et al. Weekend admission in upper GI bleeding: does it have an impact on outcome? Gastrointest Endosc 2015; 81: 1295 - 1296

34 De Groot NL, Bosman JH, Siersema PD et al. Admission time is associated with outcome of upper gastrointestinal bleeding: results of a multicentre prospective cohort study. Aliment Pharmacol Ther 2012; 36: $477-484$

35 Jairath $V$, Kahan $B C$, Logan RF et al. Mortality from acute upper gastrointestinal bleeding in the United Kingdom: does it display a "weekend effect"? Am J Gastroenterol 2011; 106: 1621 -1628 